\title{
Fabrication of room temperature operated ultra high sensitive gas sensor based on mesoporous $\mathrm{Ni}$ doped $\mathrm{WO}_{3}$ nanoparticles
}

\author{
M. S. Duraisami ${ }^{1}$, D. Benny Anburaj ${ }^{2}$, K. Parasuraman ${ }^{1 *}$ \\ ${ }^{1}$ PG \& Research Department of Physics, Poompuhar College (Autonomous) (Affiliated to Bharathidasan University, \\ Tiruchirappalli), Melaiyur - 609107, Tamil Nadu, India \\ ${ }^{2}$ PG \& Research Department of Physics, D. G. Govt. Arts College (Affiliated to Bharathidasan University, \\ Tiruchirappalli), Mayiladuthurai, Tamil Nadu, India \\ tharmamithran@gmail.com, bennyanburaj@ rediffmail.com, *resphy21@gmail.com
}

\author{
PACS 07.07.Df, 81.07.-b, 61.46-w, 61.46.Hk, 61.72Uj, 61.82.Rx
}

DOI 10.17586/2220-8054-2021-12-3-291-302

\begin{abstract}
Ultra high sensitive room temperature gas sensor based on Ni-doped $\mathrm{WO}_{3}$ nanoparticles(hereafter NPs) has been reported here. The synthesis of pure and Ni-doped $\mathrm{WO}_{3} \mathrm{NPs}$ was done by facile precipitation route. XRD studies revealed the polycrystalline monoclinic structure of the prepared samples with the preferential growth orientation along (002) crystal plane. Analysis via SEM and FE-SEM was conducted, and the micrographs showed that the synthesized samples were found to have highly porous structure with excellent dispersibility. The successful incorporation of $\mathrm{Ni}^{2+}$ ions in to $\mathrm{WO}_{3}$ lattice has been confirmed by XPS analysis. The highly improved room temperature gas sensing characteristics of $\mathrm{WO}_{3}$ by $\mathrm{Ni}$ doping is also studied using a high sensitive electrometer. Compared to undoped $\mathrm{WO}_{3}, 3$ mol. \% Ni-doped $\mathrm{WO}_{3}$ sensor showed nearly 20 -fold greater sensitivity (2641 - $200 \mathrm{ppm}$ ammonia, room temperature) with rapid response/recovery times of 40/97 s.
\end{abstract}

Keywords: $\mathrm{Ni}$ doped $\mathrm{WO}_{3}$, gas sensor, precipitation, mesoporous, room temperature.

Received: 18 February 2021

Revised: 25 March 2021

\section{Introduction}

Over the past few decades, the rapid increase of air pollution due to harmful gases released from various industrial processes has become a labyrinthine concern, which poses a threat to our environment and serious health issues to human. Toxic gases are among the vital air pollutants and their short and long term exposure may cause deleterious health effects in human such as respiratory tract ailments, memory problems, fatigue, asthma and even lung cancer [1]. From a well-being perspective, the detection of toxic gases at their early stage is an urgent demand. Therefore, toxic gas detection has become a burning topic to monitor such lethal chemical compounds and set a norm for toxic emissions. It is worth mentioning that the metal oxide semiconductors (MOSs) serve as one of the potential candidates for detecting toxic gases owing to their distinctive sensing behaviors with lower operating temperatures, availability, cost-effectiveness and compatibility with micro-electronic processes [2].

$\mathrm{WO}_{3}$ is one such important MOS, which attracts greater attention due to its unique structural, morphological, and optical properties, which have made it a suitable substance for many real time applications like gas sensors [3],

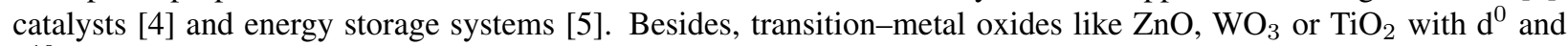
$\mathrm{d}^{10}$ electronic configurations exhibit impressive physicochemical properties and stability which are beneficial for gas sensing applications [6]. The techniques employed for the synthesis of $\mathrm{WO}_{3}$ nanostructures are also manifold. We have already reported in our previous work [7] that the precipitation method is a flexible technique for preparing monoclinic $\mathrm{WO}_{3} \mathrm{NPs}$ with optimal thermal treatment $(823 \mathrm{~K})$. Since pure $\mathrm{WO}_{3}$ contributes to a limited extent; it is necessary to improve the sensing properties through various strategies. It is believed that doping of $\mathrm{WO}_{3}$ with certain appropriate metal ions is one of the greatest possibilities to enhance the functional properties and sensing behavior of the base material.

$\mathrm{WO}_{3}$ can also be effectively deployed as a nanocomposite along with other noble and transition metals. Liu et al. [8] have investigated the ethanol and methanol sensing properties of intrinsic and Pt-doped $\mathrm{WO}_{3}$ nanorods at $220^{\circ} \mathrm{C}$. Qi et al. [9] have fabricated a $\mathrm{NO}_{2}$ sensor based on $\mathrm{Sb}$-doped $\mathrm{WO}_{3}$ nanocomposites at low temperature. Chen et al. [10] have reported $\mathrm{Ag}$ decorated $\mathrm{WO}_{3}$ nanopowder for $\mathrm{NO}$ gas detection at $250{ }^{\circ} \mathrm{C}$. $\mathrm{Li}$ et al. [11] have prepared the $\mathrm{Cr}$ incorporated $\mathrm{WO}_{3}$ nanofibers for xylene sensing. Pristine and $\mathrm{Au}$-doped $\mathrm{WO}_{3}$ nanostructures were employed as gas sensing material for enhanced $\mathrm{H}_{2}$ sensing [12].

In this context, the present work is targeted to prepare nickel-doped $\mathrm{WO}_{3} \mathrm{NPs}$ through a well-engineered precipitation technique and investigate their gas sensing characteristics at room temperature. Nickel is considered as a suitable dopant material for $\mathrm{WO}_{3}$ as its ionic radius $(0.60 \AA)$ is nearly equal to that of $\mathrm{W}(0.62 \AA)$, which would also effectively 
modify the structural and morphological properties of the base material $\left(\mathrm{WO}_{3}\right)$ [13]. As far as we know, only a very few reports are available for room temperature gas sensing properties of Ni-incorporated $\mathrm{WO}_{3} \mathrm{NPs}$ via precipitation method. The room temperature gas sensing behavior of the fabricated sensor was investigated systematically in terms of selectivity, transient response, repeatability and stability measurements.

\section{Materials and methods}

\subsection{Synthesis of pristine $\mathrm{WO}_{3} \mathrm{NPs}$}

Pure $\mathrm{WO}_{3}$ NPs were prepared according to our previous work [7], as well as the detailed preparation process has been explained as follows. In a facile precipitation technique, sodium tungstate dihydrate $\left(\mathrm{Na}_{2} \mathrm{WO}_{4} \cdot 2 \mathrm{H}_{2} \mathrm{O}\right)$ and calcium chloride dihydrate $\left(\mathrm{CaCl}_{2} \cdot 2 \mathrm{H}_{2} \mathrm{O}\right)$ were used as a precursor. Initially, $\mathrm{Na}_{2} \mathrm{WO}_{4} \cdot 2 \mathrm{H}_{2} \mathrm{O}$ and $\mathrm{CaCl}_{2} \cdot 2 \mathrm{H}_{2} \mathrm{O}$ were dissolved separately in $100 \mathrm{ml}$ of de-ionized water (DI) to obtain 1.2 and $2 \mathrm{mM}$ respectively. Later these two solutions were transferred to a beaker and stirred vigorously $(\sim 900 \mathrm{rpm})$ for 45 minutes using a magnetic stirrer at room temperature. Then the settled white precipitate $\left(\mathrm{CaWO}_{4}\right)$ was collected and washed several times with ethanol, acetone and DI. Subsequently the precipitate has been placed in hot air oven and dried at $333 \mathrm{~K}$ for 16 hours, followed by a soaking process in $50 \mathrm{ml}$ of conc. nitric acid $\left(\mathrm{HNO}_{3}\right.$, Emplura, India) for 48 hours. At the end of soaking process, the colour of the precipitate was changed from white to rich yellow, which indicates the formation of tungstite $\left(\mathrm{WO}_{3} \cdot \mathrm{H}_{2} \mathrm{O}\right)$ compound. Then the filtered precipitate was cleansed several times with ethanol, acetone and DI, and followed by a thermal calcination at $823 \mathrm{~K}$ for 2 hours, resulting in $\mathrm{WO}_{3} \mathrm{NPs}$.

\subsection{Synthesis of Ni-doped $\mathrm{WO}_{3} \mathrm{NPs}$}

The experimental procedure for the synthesis of Ni-doped $\mathrm{WO}_{3} \mathrm{NPs}$ is as follows: For the preparation of $1 \mathrm{~mol} . \%$ of Ni-doped $\mathrm{WO}_{3}$ samples, $100 \mathrm{ml}$ of $0.01 \mathrm{M}$ aqueous $\mathrm{NiCl}_{2} \cdot 6 \mathrm{H}_{2} \mathrm{O}$ solution was added to $100 \mathrm{ml}$ of $0.99 \mathrm{M}$ precipitation precursor $\left(\mathrm{CaWO}_{4}\right)$ solution. These solutions were mixed under constant magnetic stirring for 45 minutes at room temperature. Then the precipitate was filtered, washed, dried and soaked in $\mathrm{HNO}_{3}$ as described in Section 2.1 . Finally, the substance was calcined at $823 \mathrm{~K}$ for 2 hours to obtain Ni-doped $\mathrm{WO}_{3}$ samples. A similar procedure was followed to prepare 3 and 5 mol. $\%$ of Ni-doped $\mathrm{WO}_{3} \mathrm{NPs}$. The $\mathrm{WO}_{3} \mathrm{NPs}$ synthesized using $0,1,3$, and 5 mol. \% of Ni dopants were named as WN0, WN1, WN3 and WN5 respectively.

\subsection{Characterization techniques}

XRD analysis (PANalytical X'pert-pro Diffractometer equipped with $\mathrm{CuK}_{\alpha}$ radiation) was employed to determine the crystal structure of the prepared samples. The surface morphology behavior of the synthesized NPs was analyzed using SEM (ZEISS-SEM) and FE-SEM (FE-SEM, FEI Quanta 250 FEG-SEM) images. EDAX (Bruker) analysis was employed to reveal the elemental composition of the prepared samples. The surface chemistry of the prepared NPs has been investigated with the help of XPS (XPS-Thermo Fisher Scientific Inc., K Alpha, USA) spectra. The presence of functional groups in the NPs were determined using FTIR (Perkin-Elmer Spectrum Two, USA) spectra. The conventional BET and BJH methods (Nova 3200, Quantachrom Instrument Corporation, USA) were employed to measure the specific surface area and pore volume of the prepared samples respectively. The NPs were degassed at $150{ }^{\circ} \mathrm{C}$ for $3 \mathrm{~h}$ prior to the BET investigation. To disclose the defect states in the samples, PL spectra were recorded (room temperature, $\lambda_{e x}=325 \mathrm{~nm}$ ) using fluorescence spectrophotometer (Varian Cary Eclipse, USA).

\subsection{Gas sensing setupand measurements}

The systematic evaluation of sensing performance of the prepared NPs was done using a customized gas sensing setup as described in our previous work [7]. In order to construct a sensing material the synthesized NPs were mixed with certain amount of isopropyl alcohol; subsequently dispersed on a glass substrate. In which a pair of copper electrodes were used to supply a DC potential of $10 \mathrm{~V}$ and the whole sensing process was achieved in an evaporation chamber of 1 Litre. Sensing measurements were taken using a computer controlled high resistance electrometer (Keithley 6517B, USA) towards various target gases at room temperature. The following relation is used to measure the sensitivity in terms of variation in sensor resistances.

$$
S=\frac{R_{a}}{R_{g}} \quad\left(R_{a} \gg R_{g}\right) .
$$

Since $R_{a}$ and $R_{g}$ are the resistances of the fabricated sensor in air and gas respectively. 


\section{Results and discussion}

\subsection{Structural, morphological and elemental studies}

$\mathrm{X}$-ray diffraction (XRD) patterns of the pure and nickel-doped $\mathrm{WO}_{3} \mathrm{NPs}$ calcined at $823 \mathrm{~K}$ were displayed in Fig. 1(a). All the characteristic XRD peaks could be indexed according to the monoclinic (space group P2 $1 / n(14)$ ) crystal structure and are agreed with the standard JCPDS card no. 043-1035. Three major diffraction peaks for pure $\mathrm{WO}_{3}$ were obtained from (002), (020) and (200) crystal planes which correspond to the angles $2 \theta$ of 23.02, 23.61 and $24.25^{\circ}$ with lattice parameters; $a=7.297, b=7.539, c=7.688 \AA$, and $\beta=90.91^{\circ}$. For Ni-doped samples, these high intense peaks were slightly shifted towards higher angles as shown in Fig. 1(b). This can be associated to the smaller size of dopant ion $\left(0.60 \AA\right.$ for $\left.\mathrm{Ni}^{2+}\right)$ as compared to the host $\mathrm{W}^{6+}$ ion $(0.62 \AA)$ [13]. It is also observed that, all the samples exhibited the preferential growth orientation along (002) plane. The average crystallite size of all the prepared NPs can be estimated by Debye-Scherrer relation as shown in Eq. (2) and the values are given in Table 1.
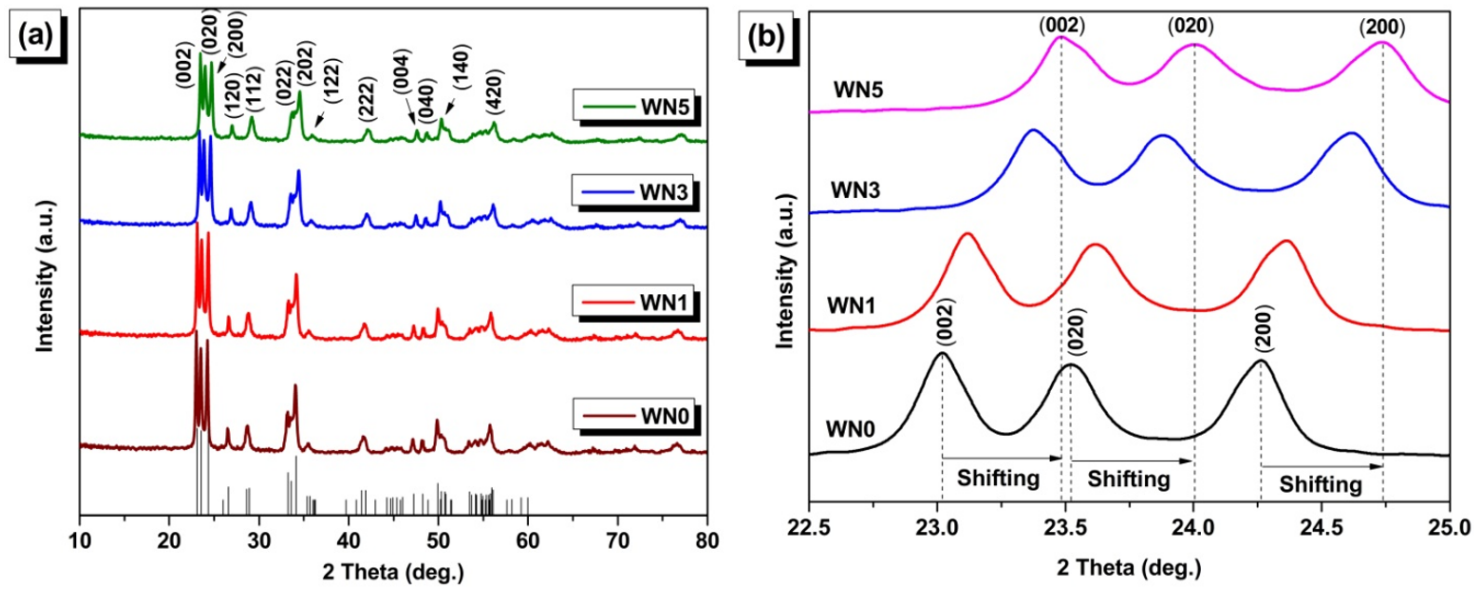

FIG. 1. (a) XRD patterns of the pure and Ni doped $\mathrm{WO}_{3} \mathrm{NPs}$ and (b) Magnified spectra of (002), (020) and (200) peaks

TABLE 1. Results obtained from XRD studies

\begin{tabular}{|c|c|c|c|}
\hline Sample & $2 \theta$ & FWHM (deg.) & Crystallite size (nm) \\
\hline \hline WN0 & 23.0230 & 0.2234 & 36.3 \\
\hline WN1 & 23.1231 & 0.2302 & 35.2 \\
\hline WN3 & 23.3731 & 0.2596 & 31.2 \\
\hline WN5 & 23.4731 & 0.2753 & 29.5 \\
\hline
\end{tabular}

Average crystallite size

$$
D=\frac{K \cdot \lambda}{\beta \cos \theta},
$$

where $K$ is the Scherrer constant, $\lambda$ is the wavelength (1.5406 $\AA$ ), $\beta$ is the full width at half-maximum and $\theta$ is the Bragg angle.

The average crystallite size was observed to be decrease with the increase of Ni dopants. This trend may be due to the effect of Ni doping, which leads to lattice distortion and associated crystal imperfections. Surprisingly, the XRD patterns of the Ni-doped $\mathrm{WO}_{3} \mathrm{NPs}$ exhibit no apparent peaks related to nickel oxides like $\mathrm{NiO}, \mathrm{NiO}_{2}$ and $\mathrm{Ni}_{2} \mathrm{O}_{3}$, or any $\mathrm{WO}_{3} / \mathrm{Ni}$ ternary oxides were found, which confirms that there is no additional phase formation in the prepared samples and also indicated that $\mathrm{Ni}$ doping was within in the solubility limit.These results confirm the formation of nickel-doped $\mathrm{WO}_{3}$ nanocrystallites without changing the monoclinic structure.

Figure 2 (a-d) illustrates the SEM images of the pristine and Ni-doped $\mathrm{WO}_{3}$ samples. A significant morphological change influenced by Ni doping was observed. The presence of Ni ions can increase crystal defects in the host material and thus induce notable changes in morphology. A decreasing trend has been observed in grain size, which may be 


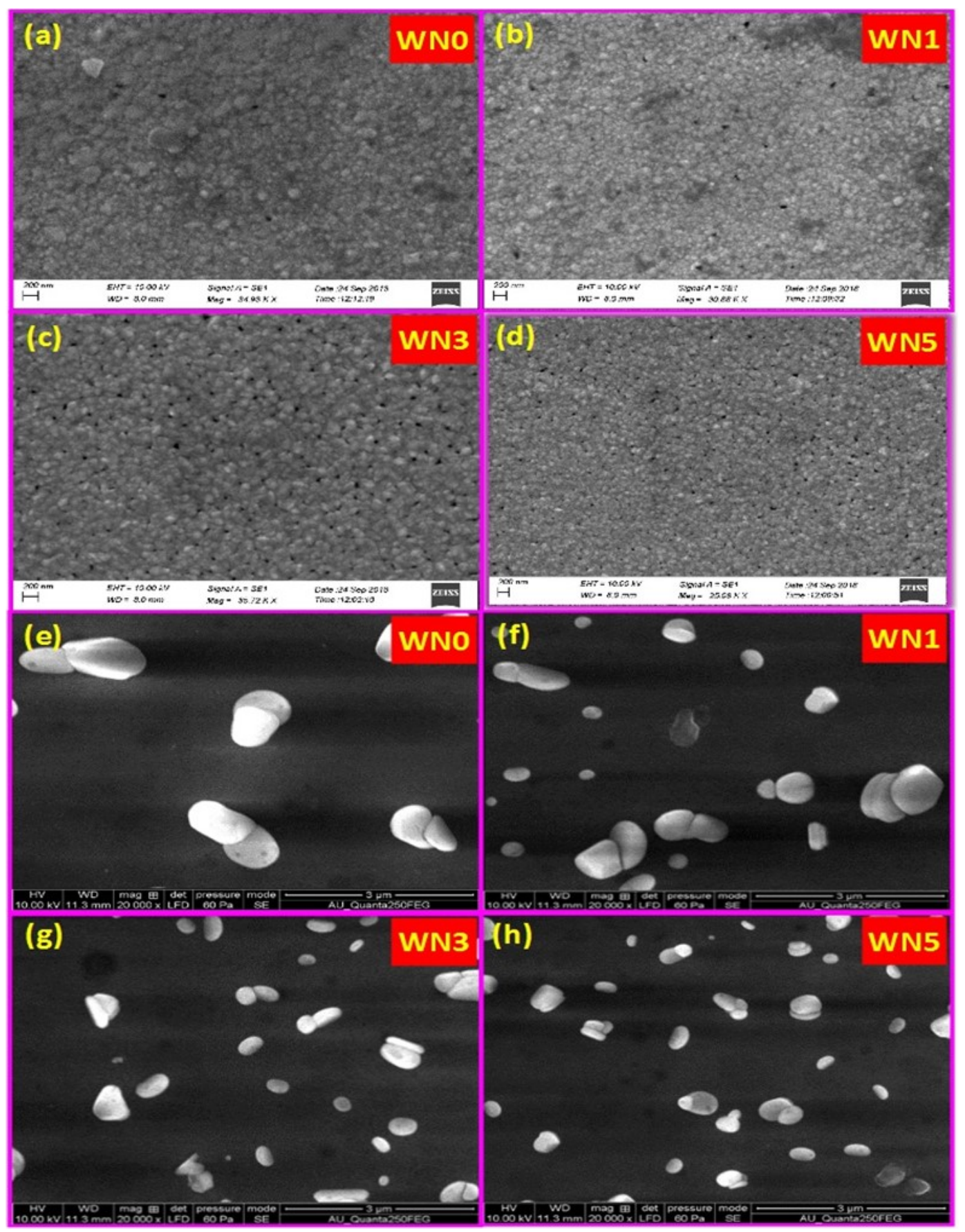

FIG. 2. $(\mathrm{a}-\mathrm{d}) \mathrm{SEM}$ images and $(\mathrm{e}-\mathrm{h}) \mathrm{FE}-\mathrm{SEM}$ micrographs of the pristine and Ni doped $\mathrm{WO}_{3}$ samples

ascribed to the grain growth inhibition nature of nickel ions [14]. A uniformly aligned nanogranular morphology with highly distributed pores were found in Ni-doped samples. In order to gain more insight into the surface morphology of the prepared NPs, FE-SEM analysis was conducted and the micrographs were displayed in Fig. 2(e-h). The obtained FE-SEM images clearly disclosed that the grains were distributed randomly with quasi-spherical shape and their dimension is further diminished upon Ni doping. We may also infer that the prepared samples have more open space with loosely packed structure. These observations are fairly consistent with the XRD studies.

The elemental composition of the prepared samples was identified through EDAX spectra as shown in Fig. 3. Fig. 3(a) reveals the presence of $\mathrm{W}$ and $\mathrm{O}$ atoms in the WNO sample and also confirmed the formation of $\mathrm{WO}_{3} \mathrm{NPs}$ without any impurities. Fig. 3(b) depicts the EDAX spectrum of WN3 sample, which ascertains the co-existence of 
$\mathrm{Ni}$ and $\mathrm{W}$ elements in the sample. In addition, a peak found at $\sim 0.85 \mathrm{keV}$ of the WN3 sample is attributed to the emitting energy level $\left(L_{\alpha}\right)$ of nickel atom, confirmed the successful incorporation of Ni species in $\mathrm{WO}_{3} \mathrm{NPs}_{\text {. }}$
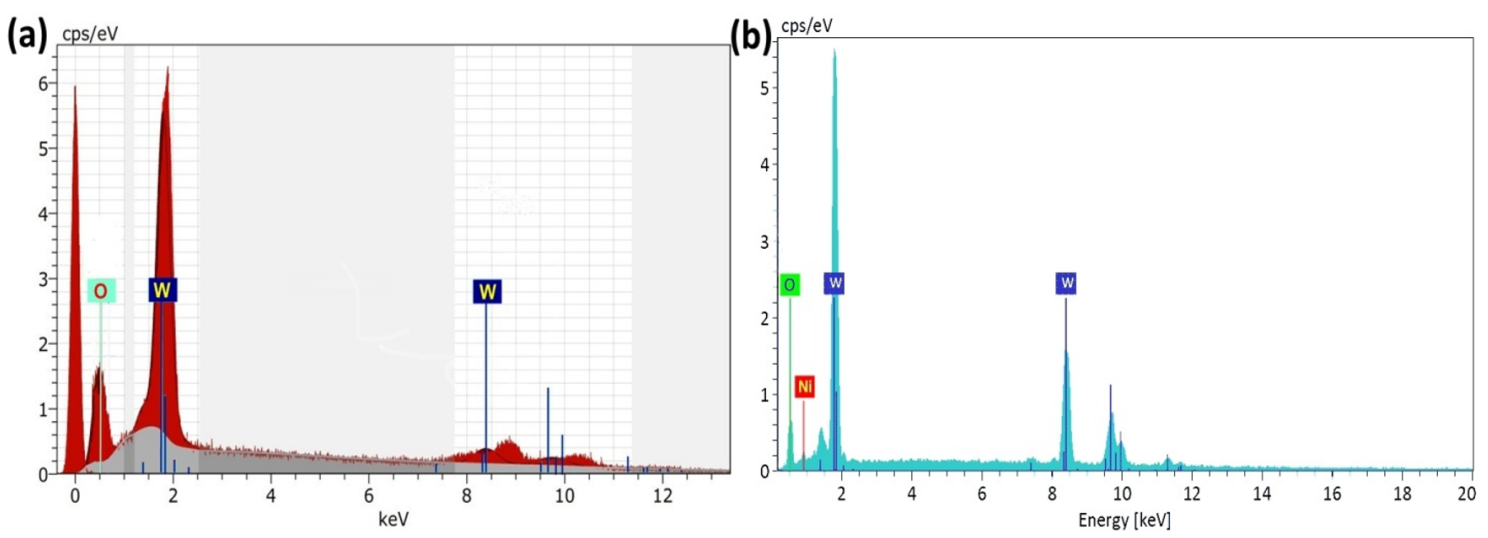

FIG. 3. EDAX spectra of (a) WN0 and (b) WN3 samples

\subsection{Functional groups}

To examine the vibrational modes on the surface of the NPs, FTIR spectra were recorded in the $400-4000 \mathrm{~cm}^{-1}$ range as displayed in Fig. 4. The peak found at $431 \mathrm{~cm}^{-1}$ belongs to the $\mathrm{W}-\mathrm{O}$ group. The stretching vibrational mode of O-W-O group is located at $607 \mathrm{~cm}^{-1}$ [15]. The other vibration modes appeared at 1381 and $1613 \mathrm{~cm}^{-1}$ are ascribed to $\mathrm{W}-\mathrm{OH}$ bond and these bands have lower absorption intensities suggesting that a very small hydration of the synthesized samples. The peak found at $3300-3600 \mathrm{~cm}^{-1}$ is due to the stretching vibrational mode of O-H groups in $\mathrm{H}_{2} \mathrm{O}$ [15]. As a result of $\mathrm{Ni}$ doping, these peaks were slightly shifted to greater wave number which probably due to the fact that the change in size of the Ni-doped $\mathrm{WO}_{3}$ NPs [16]. It is also observed from Fig. 4 that, no signal related to $\mathrm{Ni}$ or $\mathrm{NiO}$ were found, indicating the high purity of the synthesized NPs. These findings are corroborate well with the results received from XRD.

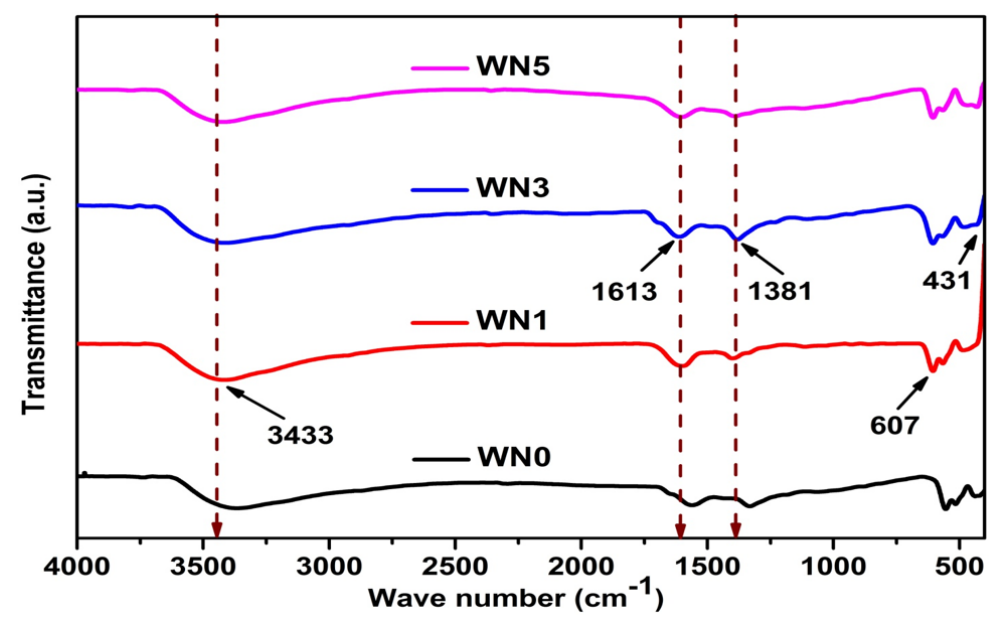

FIG. 4. FTIR spectra of the synthesized samples

\subsection{Surface analysis}

In order to disclose the chemical composition and metal ionic states in the prepared samples, XPS technique has been employed. Fig. 5 depicts the XPS spectra of WN0 and WN3 NPs. Fig. 5(a) shows the survey scan spectrum of WN0 and WN3 samples. The survey scan spectrum of WN0 confirms the presence of $\mathrm{W}, \mathrm{O}$ and $\mathrm{C}$ elements in the sample. All the peaks of WN3 sample have been observed to be similar as identified for WN0 except the presence of Ni 2p peaks (encircled) [17]. The high resolution core level XPS spectrum of W4f has been shown in Fig. 5(b); as we can see the presence of two peaks related to $\mathrm{W}_{4} \mathrm{f}_{7 / 2}($ at $35.8 \mathrm{eV})$ and $\mathrm{W}_{4} \mathrm{f}_{5 / 2}$ (at $\left.38 \mathrm{eV}\right)$ has demonstrated that the 
existence of $\mathrm{W}^{6+}$ chemical state in the sample [18, 19]. Furthermore, the W4f peaks of the WN3 sample (Fig. 5(b)) were shifted toward lower binding energy and this may be due to the effect of electronegativity of Ni ions present in the sample $[18,19]$. The doping of $\mathrm{Ni}$ ions was also responsible for the distribution of oxygen ions on the surface of $\mathrm{WO}_{3}$ and the density change of oxygen vacancies in the sample $[19,20]$, which has a crucial effect on promoting the gas sensing properties.
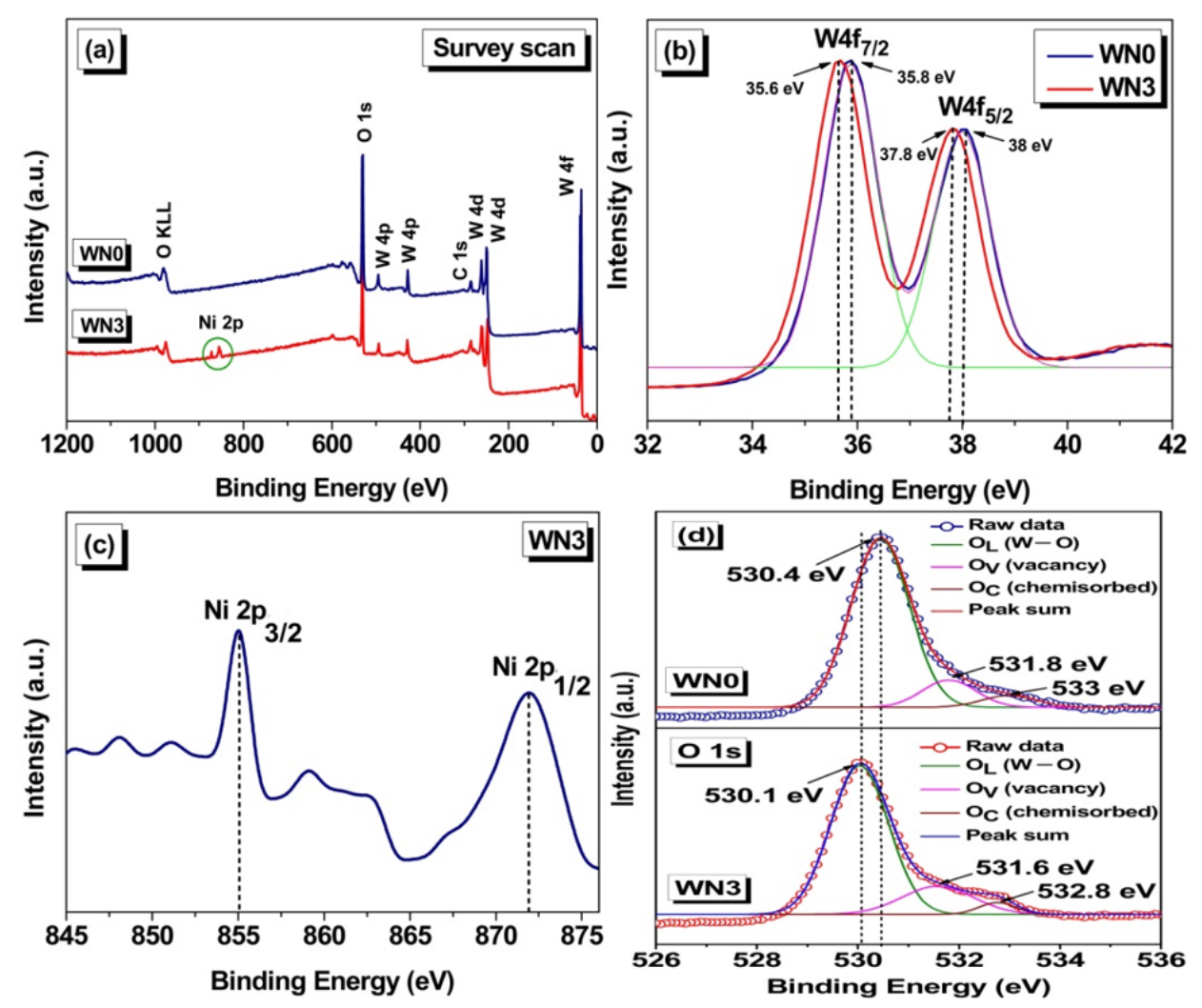

FIG. 5. (a) Survey scan spectrum of WNO and WN3 samples (b) W4f spectra (c) XPS Ni 2p spectra and (d) O 1s spectra of WN0 and WN3 samples

The core level XPS spectrum of Ni could be fitted in to two characteristic peaks with binding energies at 872 and $855.1 \mathrm{eV}$, which correspond to $\mathrm{Ni} 2 \mathrm{p}_{1 / 2}$ and $\mathrm{Ni} 2 \mathrm{p}_{3 / 2}$, respectively (Fig. 5(c)). This result clearly demonstrates that $\mathrm{Ni}$ ions exist in the form of $\mathrm{Ni}^{2+}$ ionic state in the $\mathrm{WO}_{3}$ sample $[13,19]$. The $\mathrm{O} 1 \mathrm{~s}$ spectra of WN0 and WN3 samples were displayed in Fig. 5(d) have been fitted with three peaks such as lattice oxygen $\left(\mathrm{O}_{\mathrm{L}}\right.$ peak at $\left.530.4 \mathrm{eV}\right)$, oxygen vacancy $\left(\mathrm{O}_{\mathrm{V}}\right.$ peak at $\left.531.8 \mathrm{eV}\right)$ and chemisorbed oxygen species $\left(\mathrm{O}_{\mathrm{C}}\right.$ peak at $\left.533 \mathrm{eV}\right)$ [21-24]. The $\mathrm{O}$ 1s peaks of WN3 NPs were shifted to lower binding energy, indicating the incomplete W-O binding via Ni addition or highly defective nature of the samples [25].

\subsection{BET analysis}

BET specific surface area (SSA) measurements and corresponding BJH pore size distribution of bare and Nidoped $\mathrm{WO}_{3}$ NPs were calculated using adsorption-desorption analysis and are depicted in Fig. 6(a-d). According to

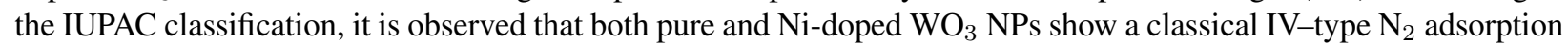
isotherm with a H3-type hysteresis loop confirming the formation of mesoporous structure. The determined SSA of $10.946,14.631,22.508$ and $31.679 \mathrm{~m}^{2} / \mathrm{g}$ with an average pore diameter of $33.981,21.567,16.687$ and $11.28 \mathrm{~nm}$ are observed for the samples WN0, WN1, WN3 and WN5 respectively. It is very clear that the doping with Ni ions ultimately increases the $\mathrm{SSA}$ of $\mathrm{WO}_{3}$ as well as make the pore-size distribution on the surface of the sample more uniform. This larger SSA with abundant pores may assist in increasing the active sites and enhance the adsorption of gas molecules which are advantageous for sensing process. 

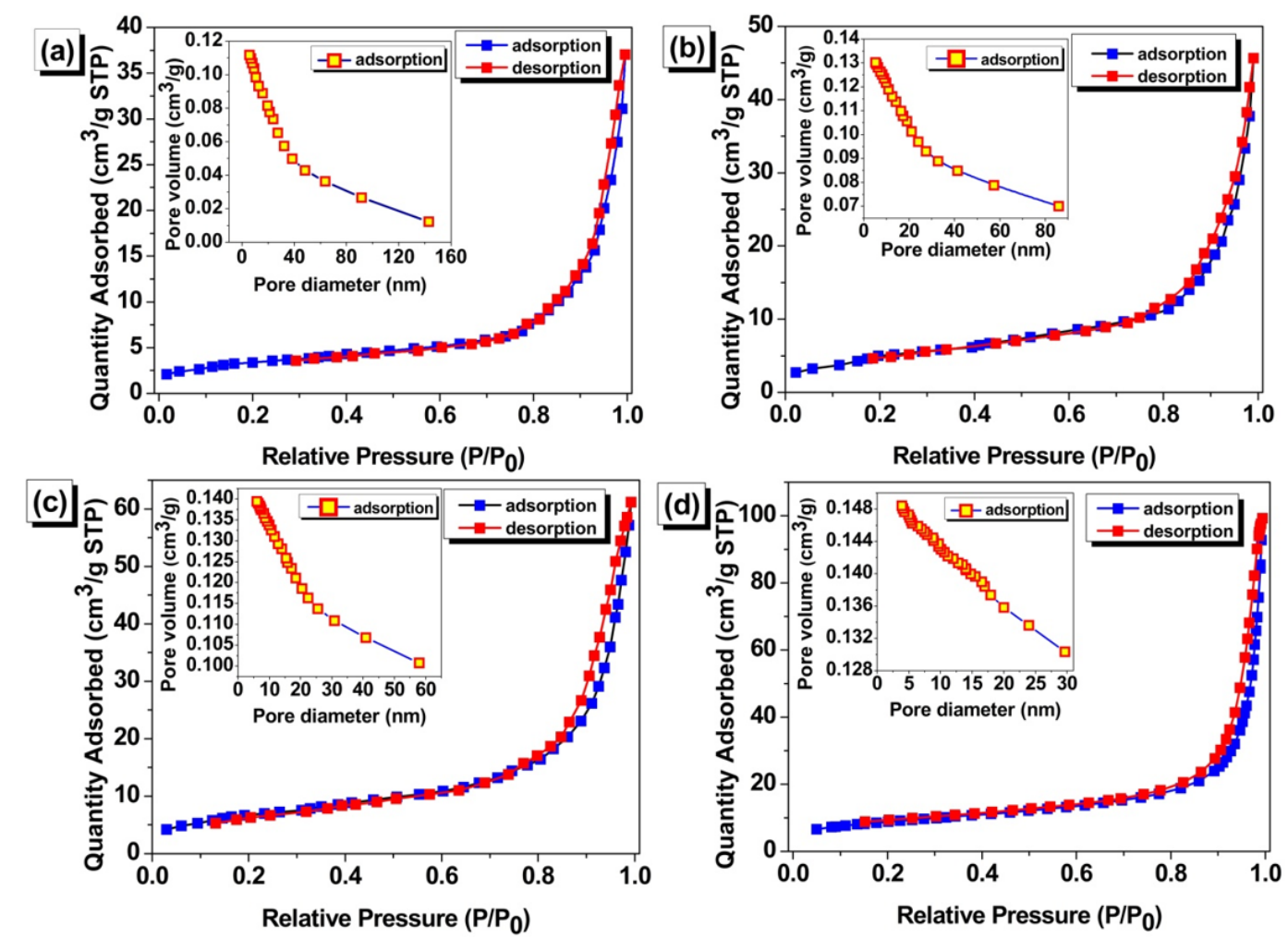

FIG. 6. $\mathrm{N}_{2}$ adsorption and desorption isotherms of (a) WN0 (b) WN1 (c) WN3 (d) WN5 samples with their corresponding pore-size distribution (inset)

\subsection{PL signatures}

PL spectra were further employed to investigate the surface processes including photo-generated electron hole pairs. PL spectra of the synthesized NPs were displayed in Fig. 7. The recombination between the electron occupying the resonant defect state in conduction band and a hole in the valence band is related to the peak cited at $378 \mathrm{~nm}$ (NUV emission). The peak located at $411 \mathrm{~nm}$ may be due to the recombination of free excitons and is generally known as near band edge (NBE) emission. The rapid electron hole pair separation is associated with the peak found at $445 \mathrm{~nm}$. The blue emission at $490 \mathrm{~nm}$ is attributed to oxygen vacancies accompanied with defect level in the band gap for its electron transition [26].

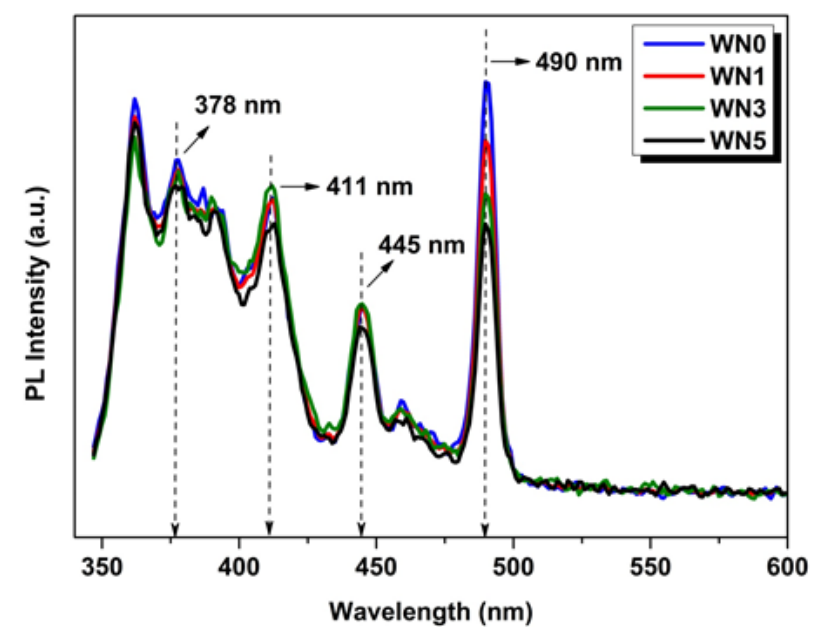

FIG. 7. Room temperature PL spectra of pure and Ni doped $\mathrm{WO}_{3} \mathrm{NPs}$ 
Interestingly, no evidence for new PL phenomena can be found after the addition of Ni dopant to the host material. However, a decrease in excitonic PL intensity of $\mathrm{WO}_{3}$ is observed which may be attributed to the electronic capture of $\mathrm{Ni}^{2+}$. By capturing an electron, $\mathrm{Ni}^{2+}$ gets transformed to $\mathrm{Ni}^{+}$which is stable to some degree with a half-filled or full-filled outermost electronic configuration. Since, the capability in capturing the photo induced electrons is greater for $\mathrm{Ni}^{2+}$ than compared to surface oxygen vacancies and defects, therefore a degeneracy in the production of excitons is occurred [13]. This results lower the excitonic PL intensity of Ni-doped $\mathrm{WO}_{3}$ samples and is ascribed to the lower recombination rate of the photo-generated electrons and holes, which is mainly affected by the greater defect density [13]. PL investigations were in glad agreement with the XPS results.

\subsection{Gas sensing studies}

Selectivity of the prepared samples was investigated in the presence of $200 \mathrm{ppm}$ of acetone $\left(\mathrm{C}_{3} \mathrm{H}_{6} \mathrm{O}\right)$, formaldehyde $\left(\mathrm{CH}_{2} \mathrm{O}\right)$, ammonia $\left(\mathrm{NH}_{3}\right)$, xylene $\left(\mathrm{C}_{8} \mathrm{H}_{10}\right)$, ethanol $\left(\mathrm{C}_{2} \mathrm{H}_{5} \mathrm{OH}\right)$, acetaldehyde $\left(\mathrm{C}_{2} \mathrm{H}_{4} \mathrm{O}\right)$, toluene $\left(\mathrm{C}_{7} \mathrm{H}_{8}\right)$ and n-butanol $\left(\mathrm{C}_{4} \mathrm{H}_{10} \mathrm{O}\right)$ gases at room temperature as shown in Fig. 8. An interesting phenomenon is noticed in Fig. 8; all the samples were highly selective towards $\mathrm{NH}_{3}$ vapor and showed a lower sensitivity to other gases. However, a considerable sensitivity is observed for acetaldehyde $(S=98)$ and formaldehyde $(S=66)$ gases. It is also evident from Fig. 8, the sensitivity of the pure $\mathrm{WO}_{3}$ NPs was found to be increased with further addition of Ni dopants and reaches a maximum value at $\mathrm{WN} 3$, indicating that the transition metal Ni remarkably improves the sensing properties of the $\mathrm{WO}_{3}$ NPs. In addition, the WN3 sample showed ultra-high selective behavior towards ammonia vapor (200 ppm) and its sensitivity $(S=2641)$ is nearly 20 times higher than that of WN0 $(S=137)$ sample. Hence all the subsequent investigations were carried out with the WN3 sample.

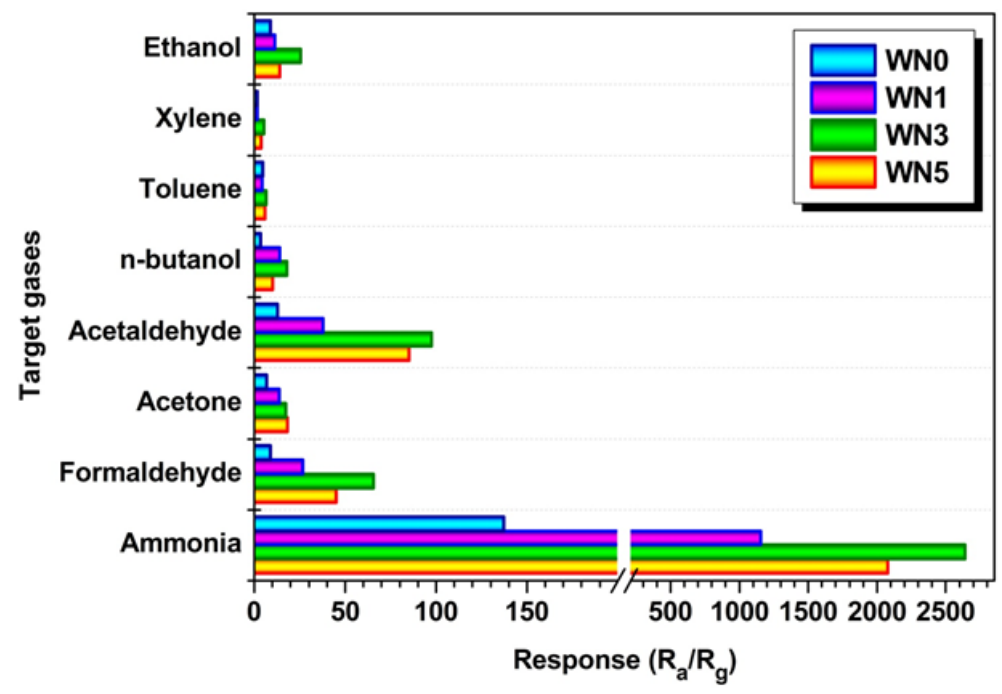

FIG. 8. Selectivity studies of the synthesized pristine and $\mathrm{Ni}$ doped $\mathrm{WO}_{3}$ samples towards $200 \mathrm{ppm}$ of different gases

Transient resistance response of WN3 sample was studied towards $5-200 \mathrm{ppm}$ of $\mathrm{NH}_{3}$ vapour at room temperature and is displayed in Fig. 9(a). It is worth mentioning that, WN3 sample shows outstanding responses to $\mathrm{NH}_{3}$ even at lower concentrations. The sensing response values of the WN3 sensor are 50.4, 62.8, 416, 717, 1118.3, 1316.8, 1680.3 and 2641.3, respectively when it is exposed to 5, 10, 25, 50, 75, 100, 150 and $200 \mathrm{ppm} \mathrm{NH}_{3}$. The sensor also exhibits a satisfying response trend towards varying concentrations of acetaldehyde and formaldehyde gases as depicted in Fig. 9(b). The WN3 sensor was tested in the range $5-1100$ ppm of $\mathrm{NH}_{3}$ and exhibited a linear response till 1000 ppm as shown in Fig. 10(a). Beyond 1000 ppm, there is no considerable improvement in sensitivity was observed. Therefore the WN3 sensor was saturated at $1100 \mathrm{ppm}$, and it could be attributed to the coverage of active sites by $\mathrm{NH}_{3}$ species. Moreover, the sensor is almost insensitive below $0.5 \mathrm{ppm}$ of $\mathrm{NH}_{3}$, hence this concentration could be considered as lower detection limit of WN3 sample. It is noteworthy that, the sensor exhibits better sensitivity to lower concentration of $\mathrm{NH}_{3}$ vapour even after exposure to $1100 \mathrm{ppm}$ of $\mathrm{NH}_{3}$, suggesting that the sensor has very good reversibility.

Figure 10 (b) shows the response and recovery trend of WN3 NPs towards $200 \mathrm{ppm}$ of $\mathrm{NH}_{3}$. The sensor resistance undergoes a dramatic decrease and reaches a saturation point $\left(R_{g}\right)$ under $\mathrm{NH}_{3}$ environment, and recovers almost to its initial baseline value $\left(R_{a}\right)$ after the removal of $\mathrm{NH}_{3}$ vapor. The response and the recovery time of WN3 sensor are 

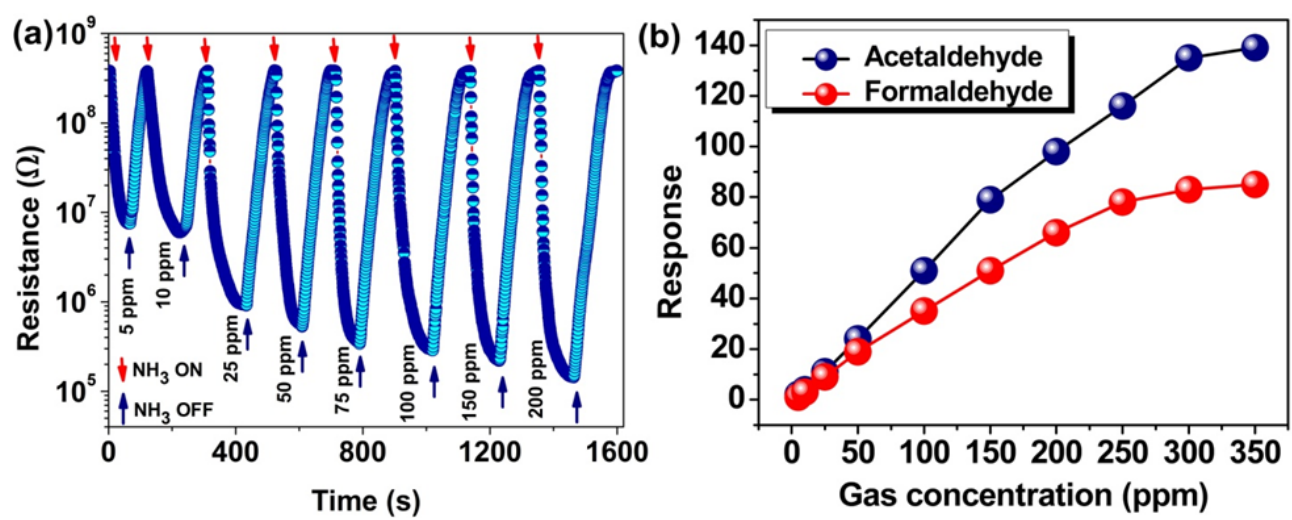

FIG. 9. (a) Transient resistance response of WN3 sample towards $5-200 \mathrm{ppm}$ of $\mathrm{NH}_{3}$ vapour at room temperature and (b) Transient response trend of WN3 sample towards varying concentrations of acetaldehyde and formaldehyde gases at room temperature
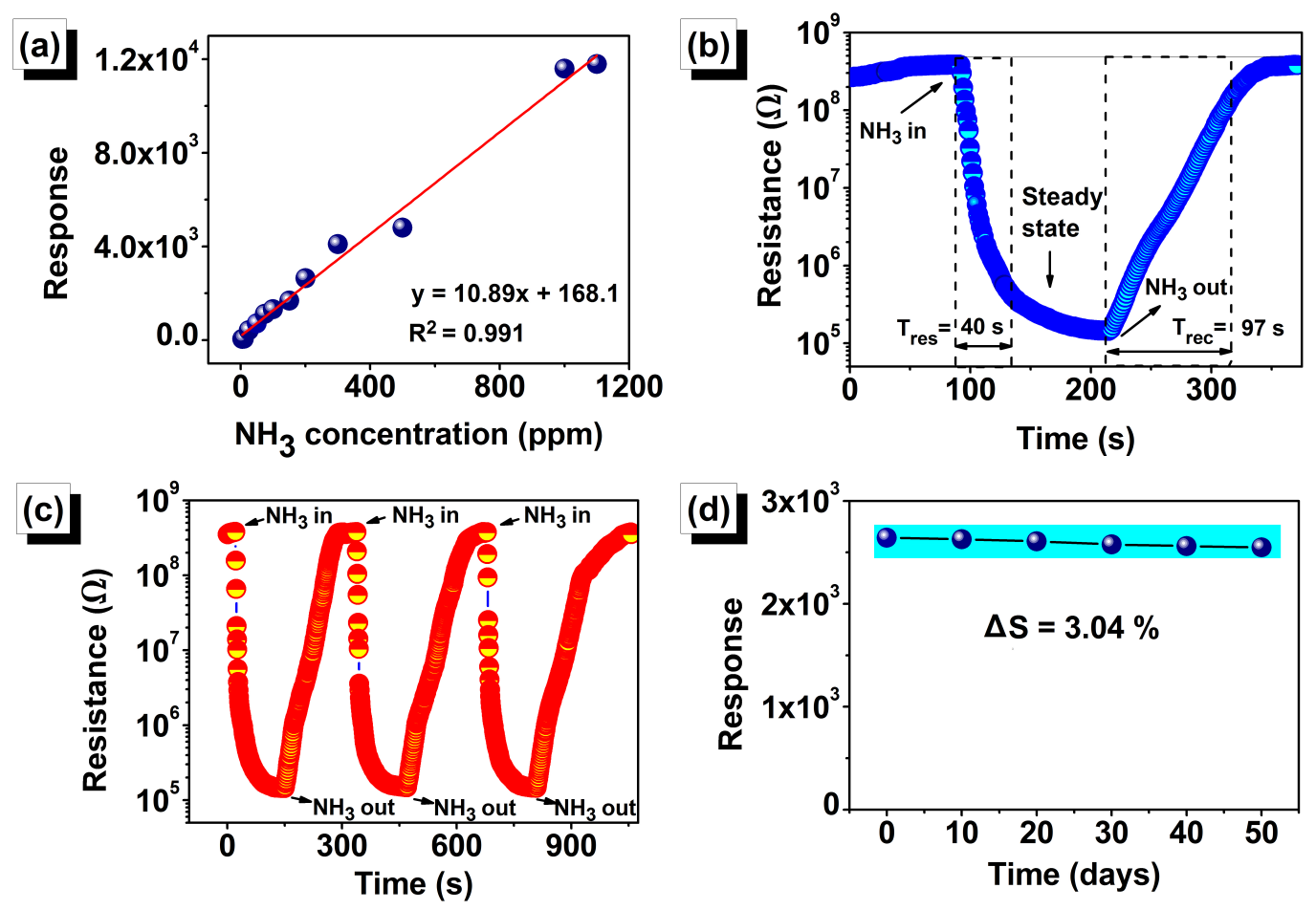

FIG. 10. (a) Response trend of WN3 sample towards different concentrations (5 - 1100 ppm) of $\mathrm{NH}_{3}$ vapour at room temperature (b) Response-recovery profile of WN3 sample towards $200 \mathrm{ppm}$ of $\mathrm{NH}_{3}$ (c) Repeatability and (d) Stability of WN3 sample towards $200 \mathrm{ppm}$ of $\mathrm{NH}_{3}$ vapour at room temperature

evaluated as 40 and $97 \mathrm{~s}$, respectively, which suggests that the rate of adsorption was faster than rate of desorption. Repeatability and long-time stability have been also measured at room temperature. The sensor shows a nearly constant signal over the three evaluation cycles towards $200 \mathrm{ppm}$ of $\mathrm{NH}_{3}$, confirming the good repeatability as shown in Fig. 10(c). The stability was found to be good towards $200 \mathrm{ppm}$ of $\mathrm{NH}_{3}$ over a period of 50 days in the interval of 10 days as displayed in Fig. 10(d). There was no significant drift found in the stability measurements and the change in sensitivity for the duration of 50 days was observed only $3.04 \%$, indicating that the high stability behavior of the sample.

Based on all the above considerations, the reported sensor has excellent figure of merits such as the capability of operating at room temperature, prompt sensing response to $\mathrm{NH}_{3}$ with quick response/recovery times, higher active detection range and long-term stability. 


\subsection{Sensing mechanism}

In general, the gas sensing behavior of MOSs especially n-type $\mathrm{WO}_{3}$ sensor can be explained in terms of the interaction between the surface chemisorbed oxygen and the gas molecules to be detected. When $\mathrm{WO}_{3} \mathrm{NPs}_{\mathrm{s}}$ were exposed to air, the oxygen molecules $\left(\mathrm{O}_{2}\right.$, below $\left.100{ }^{\circ} \mathrm{C}\right)$ were chemisorbed on the sensing surface and form oxygen ions $\left(\mathrm{O}_{2}^{-}\right)$by capturing the conduction band electrons as given in Eq. (3). This leads to the formation of a depletion region resulting in higher resistance $\left(R_{a}\right)$ of the NPs. Whereas, under a reducing gas environment such as $\mathrm{NH}_{3}$, the interaction between $\mathrm{O}_{2}^{-}$and $\mathrm{NH}_{3}$ molecules results in the liberation of electrons and are transported back to the conduction band of $\mathrm{WO}_{3}$ as given in Eq. (4). This increases the electrical conductivity of the material and thus reduce the width of the depletion region. As a result of this reaction, the sensor reaches a steady state resistance $\left(R_{g}\right)$ [7].

$$
\begin{gathered}
\mathrm{O}_{2 \text { (atmosphere) }}+\mathrm{e}_{\left(\mathrm{WO}_{3} \text { surface }\right)}^{-} \rightarrow \mathrm{O}_{2}^{-}\left(\mathrm{WO}_{3} \text { surface }\right), \\
4 \mathrm{NH}_{3}+3 \mathrm{O}_{2}^{-}\left(\mathrm{WO}_{3} \text { surface }\right) \rightarrow 2 \mathrm{~N}_{2}+6 \mathrm{H}_{2} \mathrm{O}+6 \mathrm{e}^{-} .
\end{gathered}
$$

The high selective response behavior to $\mathrm{NH}_{3}$ might be due to the following factors: (i) $\mathrm{NH}_{3}$ has the least kinetic diameter $(0.36 \mathrm{~nm})$ than other vapors, lower bond dissociation enthalpy and ionization energy which might have supported the improved surface interactions [27]. (ii) Obviously, the electron donating behavior of $\mathrm{NH}_{3}$ at effective surface regions (the areas in which the sensing layer can develop contacts with target gas) causes further increase in the density of free electrons to enhance the electrical conducting nature of the sensing material. This in-turn selective response towards $\mathrm{NH}_{3}$ [28].

Compared to bare $\mathrm{WO}_{3}$, the ultra high sensing response of $\mathrm{Ni}$-doped $\mathrm{WO}_{3}$ samples was probably due to various factors as follows, (i) The transition metal $\mathrm{Ni}$ is not only responsible for providing specific adsorption sites in the $\mathrm{WO}_{3}$ matrix but typically most of the $\mathrm{Ni}^{2+}$ ions could also perform as catalysts. It is accepted that, the p-type behavior of $\mathrm{Ni}$ ions actively improve the rate of oxidation owing to greater oxygen adsorption and thus exhibit high catalytic activity to toxic gases, hence the sensing reaction is promoted. (ii) $\mathrm{The}^{2}{ }^{2+}$ ions were allowed to displace from the coordinate center to the oxygen vacancy along the z-axis. This phenomenon can induce a deformation in the host lattice (as discussed in Section 3.3). The imperfections and dislocations have greater strain energies, which accommodate more active sites for adsorption of $\mathrm{O}_{2}$ and $\mathrm{NH}_{3}$. (iii) The smaller crystallite size would also helped in greater oxygen adsorption onto the NPs surfaces. (iv) The Ni-doped $\mathrm{WO}_{3}$ samples might have improved the inner grain interaction with analyte vapor resulting in notable switch-like change in the width of the depletion layer. (v) The large specific surface area facilitates more potential reaction sites on the surface of the sample thereby improving the performance of the sensor. (vi) Such a mesoporous structure of Ni-doped $\mathrm{WO}_{3}$ samples (as observed from SEM and BET studies) may be helpful to enhance the target-receptor interface and be in favor for the diffusion of gas molecules during the gas sensing process, which are advantageous to enhance the sensing properties of Ni-doped $\mathrm{WO}_{3}$ samples. Despite that, the excess amount of Ni dopants (WN5) will suppress the sensing characteristics of the sensor by reducing the available adsorption sites between the sensing surface and the analyte vapor [29]. Table 2 summarizes the $\mathrm{NH}_{3}$ sensing performance of our WN3 sensor in the present work and those reported in the literatures [30-34].

TABLE 2. Comparison of various sensing performances of $\mathrm{NH}_{3}$ gas sensors

\begin{tabular}{|c|c|c|c|c|c|c|c|}
\hline $\begin{array}{c}\text { Preparation } \\
\text { technique }\end{array}$ & $\begin{array}{c}\text { Dopant } \\
\text { material }\end{array}$ & Response & $\begin{array}{c}\text { Concen- } \\
\text { tration } \\
(\mathrm{ppm})\end{array}$ & $\begin{array}{c}\text { Response } \\
\text { time (s) }\end{array}$ & $\begin{array}{c}\text { Recovery } \\
\text { time (s) }\end{array}$ & $\begin{array}{c}\text { Operating } \\
\text { Tempera- } \\
\text { ture (K) }\end{array}$ & Ref. \\
\hline \hline Precipitation & $\mathrm{Ni}(3 \mathrm{~mol} . \%)$ & $2641^{a}$ & 200 & 40 & 97 & 303 & This work \\
\hline Chemical method & PANI & $4.75^{b}$ & 1000 & 15 & 45 & 303 & {$[30]$} \\
\hline Hydrolysis & $\mathrm{Ag}(3 \mathrm{molar} \%)$ & $25.1^{a}$ & 10 & 150 & 600 & 303 & {$[31]$} \\
\hline Screen printing & $\mathrm{Ru}(0.37 \mathrm{wt} \%)$ & $386^{b}$ & 1000 & 18 & 960 & 523 & {$[32]$} \\
\hline Screen printing & $\mathrm{Mn}(0.01 \mathrm{M})$ & $100^{b}$ & 50 & 10 & 50 & 303 & {$[33]$} \\
\hline Hydrothermal & $\mathrm{Pd}(1 \mathrm{M})$ & $45.7^{a}$ & 50 & 3 & 9 & 623 & {$[34]$} \\
\hline
\end{tabular}




\section{Conclusion}

In summary, pure and Ni-doped $\mathrm{WO}_{3} \mathrm{NPs}$ were successfully prepared by a facile precipitation technique. The XRD discloses a polycrystalline monoclinic crystal structure of the NPs. The SEM and FE-SEM images revealed that the samples composed of well-dispersed smaller grains with a mesoporous morphology. XPS study confirms the successful incorporation of $\mathrm{Ni}^{2+}$ ions into the $\mathrm{WO}_{3}$ lattice. BET and $\mathrm{BJH}$ analyzes demonstrate that the Ni-doped samples contain large surface area and higher textural porosity. It could be inferred from the room temperature gas sensing investigations that, the $\mathrm{Ni}$ doping has remarkable impacts on enhancing the sensing properties of $\mathrm{WO}_{3} \mathrm{NPs}_{\text {. }}$ However, the sensitivity of $\mathrm{WO}_{3} \mathrm{NPs}$ was highly improved with lower Ni doping level. Notably, the sensor fabricated

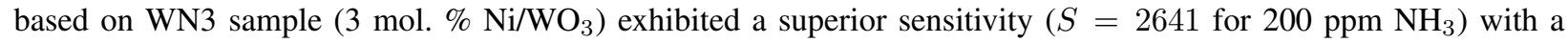
detection limit down to $0.5 \mathrm{ppm}$. Smaller grain size with huge surface area, abundant pores, rich adsorption sites, improved catalytic activity and excellent charge transport would make the Ni-doped $\mathrm{WO}_{3} \mathrm{NPs}$ as excellent sensing material for gas sensing applications and the WN3 sample can be a highly promising candidate for $\mathrm{NH}_{3}$ detection in practice, particularly in medical diagnosis systems and food sectors.

\section{Acknowledgements}

The authors gratefully acknowledge their heartfelt thanks to Nanosensor Lab, SASTRA Deemed to be University, Thanjavur, India for carried out gas sensing studies.

\section{Conflicts of interest}

The authors declare no competing interests.

\section{References}

[1] Soni V., Singh P., Shree V., Goel V. (2018) Effects of VOCs on Human Health. In: Sharma N., Agarwal A., Eastwood P., Gupta T., Singh A. (eds) Air Pollution and Control. Energy, Environment, and Sustainability, Springer, Singapore, 2018, P. 119-142.

[2] Hahn Y.B., Ahmad R., Tripathy N. Chemical and biological sensors based on metal oxide nanostructures. Chem. Commun., 2012, 48, P. 1036910385 .

[3] Wu C.H., Zhu Z., Huang S.Y., Wu R.J. Preparation of palladium-doped mesoporous $\mathrm{WO}_{3}$ for hydrogen gas sensors. J. Alloys Compd., 2019, 776, P. 965-73.

[4] Gu F., Cui Y., et al. Atomically dispersed Pt (II) on $\mathrm{WO}_{3}$ for highly selective sensing and catalytic oxidation of triethylamine. Appl. Catal. B Environ., 2019, 256, P. 117809.

[5] Wang Z., Chiu H.C., et al. Lithium Photo-intercalation of CdS-Sensitized $\mathrm{WO}_{3}$ anode for energy storage and photoelectrochromic applications. Chem. Sus. Chem., 2019, 12, P. 2220-30.

[6] Wang C., Yin L., et al. Metal oxide gas sensors: Sensitivity and influencing factors. Sensors, 2010, 10, P. 2088-2106.

[7] Duraisami M.S., Parasuraman K. High sensitive room temperature ammonia sensor based on dopant free $\mathrm{m}-\mathrm{WO}_{3}$ nanoparticles: Effect of calcination temperature. Nanosystems: Physics, Chemistry, Mathematics, 2020, 11, P. 578-589.

[8] Liu X., Zhang J., et al. Synthesis of Pt nanoparticles functionalized $\mathrm{WO}_{3}$ nanorods and their gas sensing properties. Sensors and Actuators B: Chemical, 2011, 156, P. 918-923.

[9] Qi J., Chen K., et al. Application of 3D hierarchical monoclinic-type structural Sb-doped $\mathrm{WO}_{3}$ towards $\mathrm{NO} 2$ gas detection at low temperature. Nanoscale, 2018, 10, P. 7440-7450.

[10] Chen L., Tsang S.C. Ag doped $\mathrm{WO}_{3}$-based powder sensor for the detection of $\mathrm{NO}$ gas in air. Sensors and Actuators B: Chemical, 2003, 89, P. 68-75.

[11] Li F., Ruan S., et al. Synthesis and characterization of Cr-doped $\mathrm{WO}_{3}$ nanofibers for conductometric sensors with high xylene sensitivity. Sensors and Actuators B: Chemical, 2018, 265, P. 355-364.

[12] Xiang Q., Meng G.F., et al. Au Nanoparticle Modified $\mathrm{WO}_{3}$ Nanorods with Their Enhanced Properties for Photocatalysis and Gas Sensing. The Journal of Physical Chemistry C, 2010, 114, P. 2049-2055.

[13] Faisal Mehmood, Javed Iqbal, Ismail M., Arshad Mehmood. Ni doped $\mathrm{WO}_{3}$ nanoplates: An excellent photocatalyst and novel nanomaterial for enhanced anticancer activities. Journal of Alloys and Compounds, 2018, 746, P. 729-738.

[14] Gattu K.P., Ghule K., et al. Bio-green synthesis of Ni-doped tin oxide nanoparticles and its influence on gas sensing properties. RSC Adv., 2015, 5, P. 72849.

[15] Delichere P., Falaras P., Froment M., Goff A.H.L. Electrochromism in anodic $\mathrm{WO}_{3}$ films I: preparation and physicochemical properties of films in the virgin and coloured states. Thin Solid Films, 1988, 35, P. 161.

[16] Abhudhahir M.H.S., Kandasamy J. Photocatalytic effect of manganese doped $\mathrm{WO}_{3}$ and the effect of dopants on degradation of methylene blue. J. Mater. Sci.: Mater. Electron., 2015, 26, P. 8307-8314.

[17] Zhou J., Wei Y., et al. Electrochromic properties of vertically aligned $\mathrm{Ni}$-doped $\mathrm{WO}_{3}$ nanostructure films and their application in complementary electrochromic devices. Journal of Materials Chemistry C, 2016, 4, P. 1613-1622.

[18] Wang Y., Liu B., et al. Low-temperature $\mathrm{H}_{2} \mathrm{~S}$ detection with hierarchical Cr-doped $\mathrm{WO}_{3}$ microspheres. ACS Appl. Mater. Interfaces, 2016, 8, P. 9674-9683.

[19] Dakhel A.A., Ashoor H. Synthesis of semi ferromagnetic Ni doped $\mathrm{WO}_{3}$ nanoparticles by precipitation method: evaluation of effect of treatment in hydrogen gas. Mater. Chem. Phys., 2019, 230, P. 172-177.

[20] Grosvenor A.P., Biesinger M.C., Smart R.St.C., McIntyre N.S. New interpretations of XPS spectra of nickel metal and oxides. Surf. Sci., 2006, 600, P. 1771-1779. 
[21] Bai S., et al. Gas sensing properties of Cd-doped ZnO nanofibers synthesized by the electrospinning method. J. Mater. Chem. A, 2014, 2, P. 16697-16706.

[22] Lee Y.A., et al. Highly sensitive gasochromic $\mathrm{H}_{2}$ sensing by nano-columnar $\mathrm{WO}_{3}-\mathrm{Pd}$ films with surface moisture. Sens. Actuators B, 2017, 238, P. 111-119.

[23] Tong M., et al. Facile preparation of amorphous carbon-coated tungsten trioxide containing oxygen vacancies as photocatalysts for dye degradation. J. Mater. Sci., 2019, 54, P. 10656-10669.

[24] Ta T.K.H., et al. Surface functionalization of $\mathrm{WO}_{3}$ thin films with (3-Aminopropyl) triethoxysilane and succinic anhydride. J. Electron. Mater., 2017, 46, P. 3345-3352.

[25] Vuong N.M., Kim D., Kim H. Porous Au-embedded $\mathrm{WO}_{3}$ nanowire structure for efficient detection of $\mathrm{CH}_{4}$ and $\mathrm{H}_{2} \mathrm{~S} . \mathrm{Sci}$. Rep., 2015, 5, P. 11040 .

[26] Kwangyeol Lee, Won Seok Seo, Joon T. Park. Synthesis and Optical Properties of Colloidal Tungsten Oxide Nanorods. J. Am. Chem. Soc., 2003, 125, P. 3408-3409.

[27] Nayak A.K., Ghosh R., et al. Hierarchical Nanostructured $\mathrm{WO}_{3}-\mathrm{SnO}_{2}$ for Selective Sensing of Volatile Organic Compounds. Nanoscale, 2015, 7, P. 12460-12473.

[28] Mani G.K., Rayappan J.B.B. A highly selective room temperature ammonia sensor using spray deposited zinc oxide thin film. Sensors Actuators, B Chem., 2013, 183, P. 459-466.

[29] Yongjiao Sun, Lin Chen, et al. Synthesis of $\mathrm{MoO}_{3} / \mathrm{WO}_{3}$ composite nanostructures for highly sensitive ethanol and acetone detection. J. Mater. Sci., 2017, 52, P. 1561-1572.

[30] Shukla S.K., Singh N.B., Rastogi R.P. Efficient ammonia sensing over zinc oxide/polyaniline nanocomposite. Indian J. Eng. Mater. Sci., 2013, 20, P. 319-324.

[31] Haixin Liu, Wenhao Shen, Xiaoquan Chen. A room temperature operated ammonia gas sensor based on $\mathrm{Ag}_{-} \mathrm{decorated} \mathrm{TiO}{ }_{2}$ quantum dot clusters. RSC Adv., 2019, 9, P. 24519-24526.

[32] Wagh M.S., Jain G.H., et al. Modified zinc oxide thick film resistors as $\mathrm{NH}_{3}$ gas sensor. Sens. Actuators B Chem., 2006, 115, P. $128-133$.

[33] Patil L.A., Sonawane L.S., Patil D.G. Room temperature ammonia gas sensing using $\mathrm{MnO}_{2}$-modified ZnO thick film resistors. J. Mod. Phys., 2011, 2, P. 1215-1221.

[34] Yi Z., Zheng L., et al. Enhanced ammonia sensing performances of Pd-sensitized flowerlike ZnO nanostructure. Sens. Actuators B Chem., 2011, 156, P. 395-400. 